\title{
O ProEMI e o ensino médio em tempo integral no Brasil
}

\section{ProEMI and full-time high school in Brazil}

\section{El ProEMI y la escuela secundaria de tiempo completo en Brasil}

\author{
Andréa Giordanna Araujo da Silva' \\ Universidade Federal de Alagoas, Professora no Departamento de Educação
}

Resumo: $\bigcirc$ construto apresenta a trajetória histórica e político-ideológica do Programa Ensino Médio Inovador (ProEMI), que, desde 2009, tem-se caracterizado como principal política federal de implantação do ensino médio em tempo integral no Brasil. Utilizam-se os documentos-orientadores do Programa (BRASIL, 2009b, 2011, 2013, 2014, 2016c) como fontes de pesquisa para identificar as diferentes perspectivas ideológicas e os objetivos políticos delineados para o Programa federal no período de 2009 a 2016 . Por conseguinte, apresenta-se o cenário de disputa ideológica em que são formatadas e implantadas as políticas de ensino médio no Brasil desde a década de 1990 e o significado do termo reestruturação como eixo estruturador inicial das práticas pedagógicas do ProEMI como ação política indutora da melhoria da qualidade do ensino médio no Brasil. Discute-se, ainda, a criação do ProEMI/JF que iniciou o processo de silenciamento da base filosófica do ProEMI: a educação integral.

Palavras-chave: ProEMI. Ensino médio. ProEMI/JF. Educação integral. Ensino de tempo integral.

Abstract: The construct has a historical and political-ideological trajectory of the High School Innovation Program (ProEMI), since 2009, has been characterized with the main federal policy of implementation of full-time high school in Brazil. The Program's guiding documents (BRASIL, 2009b, 2011, 2013, 2014, 2016c) are used as sources of research to identify different ideological and global perspectives for the federal Program in the period 2009-2016. Therefore, the study present the scenario of ideological dispute in which the high school

\footnotetext{
Doutora em Educação pela Universidade Federal de Pernambuco; Mestre em Educação pela Universidade Federal de Alagoas.
} 
programs are formatted and implemented as policies of secondary education in Brazil from 1990. The study discussed the meaning of the term restructuring as the initial structuring axis of the pedagogical practices of ProEMI, as political action for inducing the quality of the high school in Brazil. It was also discussed the creation of ProEMI/JF, that started the process of silencing the philosophical basis of ProEMI: the integral education.

Keywords: ProEMI. High school. ProEMI/JF. Integral education. Full-time education.

Resumen: El estudio presenta la historia del Programa Escuela Secundaria Innovadora (ProEMI), que, desde 2009, es la principal política federal para introducir la enseñanza media a tiempo completo en Brasil. De esa manera, los documentos del Programa (BRASIL, 2009b, 201 1, 2013, 2014, 2016c) se utilizan como fuentes de investigación. Se utilizan para identificar diferentes ideologías y los objetivos políticos del Programa federal para el período 2009-2016. Se estudia el escenario de disputas ideológicas de las políticas de educación secundaria implementadas en Brasil desde la década de 1990 y el significado de reestructuración como eje estructural inicial de prácticas pedagógicas y de la acción política para la calidad de la enseñanza secundaria en Brasil. También se estudia la creación de ProEMI/JF, que comenzó el proceso de silenciar la base filosófica del ProEMI: la educación integral.

Palabras clave: ProEMI. Escuela secundaria. ProEMI/JF. Educación integral. Escuela de jornada ampliada.

\section{INTRODUÇÃO}

$\bigcirc$ artigo apresenta discussões ampliadas das reflexões desenvolvidas durante a realização do Doutorado em Educação (2012-2016). ${ }^{2}$ No texto discute-se acerca da trajetória histórica e político-ideológica do Programa Ensino Médio Inovador (ProEMI), que, desde 2009, tem-se caracterizado como a principal política federal de implantação do ensino médio em tempo integral

\footnotetext{
2 A formação realizou-se no Programa de Pós-Graduação em Educação da Universidade Federal de Pernambuco.
} 
no Brasil. ${ }^{3}$ Utilizamos os documentos orientadores do Programa (BRASIL, 2009b, 201 1, 2013, 2014, 2016c) como fontes de pesquisa para identificar as diferentes perspectivas ideológicas e os objetivos políticos delineados para o Programa federal no período de 2009 a 2016. Buscamos, também, apresentar o cenário de disputa ideológica em que são formatadas e implantadas as políticas de ensino médio no Brasil desde 1990.

Para interpretar os conflitos e as contradições expressas nos discursos que dão sentido e significado político e social à implantação do ensino médio em tempo integral no Brasil (2009-2016), mais especificamente à criação do ProEMI, o Silenciamento ou Política do Silêncio, um conceito da Análise do Discurso desenvolvida nos escritos de Orlandi (2007), serviu de ferramenta analítica.

Silenciamento ou "Política do Silêncio" (ORLANDI, 2007), como artifício de produção de sentidos, materializa-se de duas formas: por meio da interdição ou censura que proíbe o dizer e anula a produção de sentidos e significados, ou pela substituição de um discurso por outro. Isso ocorre quando algo é dito para que outra coisa não possa ser dita e reproduza sentidos e significados diferentes daqueles que se espera que o sujeito acesse e se aproprie.

A forma mais comum de silenciamento no cenário político governamental brasileiro tem sido a promoção de reformas curriculares que impõem aos educandos a apropriação (internalização) de lógicas, hábitos e conteúdos associados a interesses privados (meritocracia, status e lucro) e às relações de mercado (oferta de incentivos monetários aos professores ${ }^{4}$ em troca da elevação do desempenho acadêmico do estudante e consenso), que recusam as condições econômicas e culturais vividas e reproduzidas pelos estudantes (experiência social coletiva) como processos de formação.

Por conseguinte, na primeira parte do texto, apresentamos a análise histórica das políticas de ensino médio a partir de 1990 no Brasil; na sequência, as características estruturais e os interesses políticos que deram sentido à implantação do ProEMI. Também realizamos a análise das diferentes fases de

\footnotetext{
3 As discussões desenvolvidas no artigo são parte das reflexões originadas da pesquisa de doutorado realizada no período de 2012 a 2016.

4 Referência aos programas de bonificação a professores e gestores e de premiação das escolas que apresentam elevação do desempenho dos estudantes nos exames nacionais de aprendizagem.
} 
execução do Programa federal (2009-2016). Discorremos, portanto, sobre a incursão do setor empresarial nas políticas de educação básica e seus efeitos na estruturação e na definição dos objetivos das práticas escolares, por meio da identificação da estrutura e dos objetivos do Programa Ensino Médio Inovador/ Jovem de Futuro (ProEMI/JF). Buscamos, ainda, pautar as transformações transcorridas pelo ProEMI como indícios das alterações outorgadas ao ensino médio com a criação da Lei n. 13.415, de 16 de fevereiro de 2017 (BRASIL, 2017), que institui uma reforma (retrocesso) para o ensino médio no Brasil.

\section{AS POLÍTICAS DE ENSINO MÉDIO NO BRASIL: PERCURSOS CONTEMPORÂNEOS}

Na década de 1980, com o movimento de redemocratização do Brasil, iniciou-se um processo de debate teórico e político, de âmbito nacional, sobre os fundamentos e as formas de funcionamento da educação secundária. Segundo Rodrigues (2005, p. 260), um marco desse processo, para o campo de pesquisa em Educação, foi a realização do Seminário Choque Teórico em 1987, 5 posteriormente apresentado por Saviani (1989) no texto Sobre a concepção de politecnia, que serviu de documento indutor para uma reflexão mais aprofundada sobre a relação entre o ensino médio e o ensino técnico no Brasil. Na década de 1990, todavia, com a instituição dos princípios neoliberais como instrumentos de orientação de gestão no setor público, outros discursos e práticas tornaram-se hegemônicos no campo educacional.

A influência dos interesses no mercado competitivo na definição dos objetivos do ensino público foi muito aguda na elaboração das diretrizes e dos modelos de ensino médio implantados no País nos anos 1990, e uma de suas materialidades políticas foi a instituição do Decreto n. 2.208 /97, que desvinculava o ensino médio da formação técnica.

5 O Seminário foi promovido pelo Politécnico da Saúde Joaquim Venâncio, hoje, Escola Politécnica de Saúde Joaquim Venâncio (RODRIGUES, 2005). 
Segundo o discurso governamental do período, os cursos profissionais desenvolvidos em associação com a educação média regular tinham um custo elevado e não estavam atendendo de forma imediata às demandas do mercado de trabalho competitivo. Logo, o dispositivo oficial serviu como mecanismo político para reforçar o dualismo estrutural da educação secundária no Brasil, pois legitimou formalmente a separação do ensino profissional da formação geral.

Nos sistemas de ensino público, institucionalizaram-se, também, os modelos de ensino e de avaliação por competências e habilidades, seguindo as orientações das Diretrizes Curriculares Nacionais para o Ensino Médio (DCNEM), Resolução CEB n. 3, de 26 de junho de 1998, as quais apresentavam o vínculo da "educação com o mundo do trabalho e a prática social, consolidando a preparação para o exercício da cidadania e propiciando preparação básica para o trabalho" como objetivo principal para o ensino médio (BRASIL, 1998, art. 1º).

A realização de atividades laborais que gerassem renda imediata era a meta do Estado para a formação do trabalhador, por isso o texto oficial apresentava uma "ênfase excessiva na flexibilização, autonomia e descentralização do currículo, subordinando a educação às demandas do mundo do trabalho." (MOEHLECKE, 2012, p. 39).

Nesse contexto, os objetivos pedagógicos das diretrizes foram estruturados por meio da demarcação de áreas de conhecimento: Linguagens, Códigos e suas Tecnologias, Ciências da Natureza, Matemática e suas Tecnologias, Ciências Humanas e suas Tecnologias, que deveriam ter a interdisciplinaridade e a contextualização como princípios políticos para a reforma do currículo escolar. Em 1999, foram instituídos os Parâmetros Curriculares Nacionais do Ensino Médio (PCNEM), com o objetivo de criar referenciais nacionais para a educação secundária e reforçar a perspectiva do ensino médio como instrumentalização para a inserção no mercado de trabalho (LOPES, 2002).

$\bigcirc$ que ocorreu, porém, especialmente no ensino médio não profissional, foi o silenciamento como forma de supressão do sentido político e social (ORLANDI, 2007) das disciplinas escolares como campos de saberes com objetivos, conteúdos e práticas pedagógicas específicas. Isso ocorreu porque 
a contextualização se apresentava como um conceito ambíguo, que, embora aparentasse desejar a aproximação do currículo escolar com o universo social dos sujeitos das escolas, estava atravessado pelas perspectivas instrumentais do mercado competitivo, a quem interessava o desenvolvimento de habilidades e as competências que seriam "avaliadas nos exames centralizados e nos processos de trabalho." (LOPES, 2002, p. 392-393).

○ ideário de contextualização estava diretamente relacionado com o quadro econômico em transformação e as novas capacidades requeridas ao trabalhador para permanecer ou ingressar no mundo do trabalho. Segundo Ramos (2002, p. 401), o que se pretendeu foi "reordenar conceitualmente a compreensão da relação trabalho/educação, desviando o foco dos empregos, das ocupações e das tarefas para o trabalhador, em suas implicações subjetivas com o trabalho." Assim, o entendimento da realidade deveria ser reduzido aos acontecimentos imediatos experienciados pelos homens, e as "[...] desigualdades sociais e a distribuição dos bens sociais são apresentados como relações dadas e naturais, que se reproduzem de forma linear, progressiva e espontânea." (RAMOS, 2009, p. 59).

As perspectivas de reforma do currículo escolar estavam expressas nos objetivos do Programa Acorda Brasil: Está na Hora da Escola, proposto pelo primeiro Governo de Fernando Henrique Cardoso (FHC 1995-1998). As concepções pedagógicas que davam sentido ao Programa se configuraram como produtos políticos, instituídos por meio do processo de hibridização de teorias com a finalidade de promover a ressignificação dos sentidos políticos, sociais e culturais de conceitos como ensino e aprendizagem, trabalho e desempenho docente e avaliação, com o objetivo de obter o controle e a hierarquização de poderes na definição dos programas escolares e o consenso dos sujeitos da escola (professores, gestores, estudantes e comunidades).

É preciso ilustrar que, nesse período, o Governo estreitou a relação com organismos internacionais de crédito, em especial com o Fundo Monetário Internacional (FMI) e o Banco Mundial (BM), que passaram a influenciar as políticas nacionais e sociais. Assim, as DCNEM (1998) e os PCNEM (1999) também buscavam adequar a organização dos sistemas de ensino às orientações políticas e pedagógicas de instituições externas (MELO, 2004). 
Por conseguinte, é no quadro histórico descrito, especificamente no período da acirrada perspectiva neoliberal no campo político-educacional, que o termo reestruturação aparece como um acontecimento político, imerso em um conflito ideológico e constitutivo do movimento dialético: a politecnia e a polivalência, o ensino médio integrado e a formação para o (trabalho) mercado competitivo.

Assim, a propositiva de reestruturação do ensino médio surge no discurso político governamental mais fortemente em 2003, ${ }^{6}$ como a necessidade de substituir a estrutura inflexível do paradigma escolar tradicional por um currículo diversificado. A reestruturação era tida como um espaço de disputa política pelo estabelecimento de um quadro teórico-conceitual e político-pedagógico para o ensino médio que substituísse a formação para o desenvolvimento de competências pelo trabalho; como princípio educativo que rompesse com o ciclo histórico pragmático e produtivista e com a estrutura dualista e fragmentada que tem dado sentido político e social ao ensino secundário no Brasil (FRIGOTTO; CIAVATTA; RAMOS, 2012; KUENZER, 2011 ).

Areestruturação, portanto, pretendeu produzir um sentido antagônico ao das reformas políticas imprimidas pelo governo federal na década de 1990. $\bigcirc$ termo carregava o interesse da constituição de uma escola que atendesse às necessidades e aos interesses da classe trabalhadora. Por isso, tomava o ensino médio como um direito e como uma necessidade social e política para os jovens (AZEVEDO; REIS, 2013) e "[...] entende a integração como unidade entre as disciplinas e formas de conhecimento nas instituições escolares." (RAMOS, 2005, p. 1 14).

Assim, duas perspectivas, dois projetos de formação apresentam-se de forma mais evidente na disputa político-governamental e nas discussões teórico-ideológicas sobre o papel do ensino médio: uma que se volta para a constituição da politecnia como fundamento do ensino secundário, articulado ou não com a formação profissional, e outra que observa o currículo diversificado como fundamento para a reconfiguração das práticas pedagógicas (ou somente

6 Com a realização de dois eventos indutores da discussão em âmbito nacional: o Seminário Nacional Ensino Médio: Construção Política, em 2003, e o Seminário Nacional de Educação Profissional: Concepções, experiências, problemas e proposta, em 2004. 
didáticas) do ensino médio, tendo em vista a "educação para o trabalho" e o desenvolvimento pessoal (rede discursiva empresarial).

Em âmbito governamental federal, a perspectiva da reestruturação ganha forma com a criação, em 2009, do Programa Ensino Médio Inovador (ProEMI), que correspondia a uma das ações do Plano de Desenvolvimento da Educação (PDE), instituído em 2007, que tinha, entre outras metas, a de promover a qualificação de ensino público por meio de diversificação das práticas pedagógicas e da ampliação do tempo escolar, tendo o trabalho como princípio educativo e a ciência, a cultura e a tecnologia como eixos formativos.

\section{PROGRAMA ENSINO MÉDIO INOUADOR: MOUIMENTO HISTÓRICO E CONTEÚDO POLÍTICO}

Instituído pela Portaria n. 971, de 09 de outubro de 2009 (BRASIL, 2009a), o ProEMI correspondia a uma proposta de inovação do currículo do Ensino Médio, encaminhada pelo Ministério de Educação e aprovada pelo Conselho Nacional de Educação (CNE), instituição que assume a função de validar a legitimidade social e política das políticas do governo federal. Entretanto, o processo e o interesse por sua elaboração percorreram vários caminhos antes de sua validação pelo CNE.

Em 2008, “[...] a Diretoria de Concepções e Orientações Curriculares para a Educação Básica - DCOCEB/SEB/MEC propôs a avaliação do Ensino Médio Integrado - política curricular de referência do período de 20022010, implantada por meio do Decreto n 5.154/04." (ISLEB, 2014, p. 57). $\bigcirc$ diagnóstico possibilitou identificar o distanciamento existente entre a política de ensino médio integrado (à educação profissional) e as demandas materiais e pedagógicas das escolas não profissionais e propiciou a escrita do texto Ensino médio integrado: uma perspectiva abrangente na política pública educacional - versão preliminar, que propunha a criação da Política Nacional para o Ensino Médio. Nesse documento, a Escola Unitária é tratada como fundamento para elaboração de uma política nacional de ensino médio (ISLEB, 2014, p. 57). 
Também, em 2008, "[...] foi firmada a parceira entre o MEC e a Secretaria de Assuntos Estratégicos (SAE) da Presidência da República para a realização de um Grupo de Trabalho (GT) Interministerial [com o objetivo de] discutir a reestruturação e expansão do Ensino Médio no Brasil." (ISLEB, 2014 , p. 59-60). As discussões do GT originaram o documento Reestruturação e expansão do ensino médio no Brasil (BRASIL, 2008). O teor político do texto atestava que

[...] a identidade do ensino médio se define na superação do dualismo entre propedêutico e profissional. Importa que se configure um modelo que ganhe uma identidade unitária para esta etapa da educação básica, e que assuma formas diversas e contextualizadas da realidade brasileira. [...]

Busca-se uma escola que não se limite ao interesse imediato, pragmático e utilitário. Uma formação com base unitária, no sentido de um método de pensar e de compreender as determinações da vida social e produtiva que articule trabalho, ciência e cultura na perspectiva da emancipação humana. (BRASIL, 2008, p. 8).

Por conseguinte, o ProEMI foi inspirado no documento produzido pelo GT Interministerial, mas também nas propostas extraídas do Seminário Nacional Ensino Médio: Construção Política, realizado em maio de 2003, pela Secretaria de Educação Média e Tecnológica (Semtec), que foi desmembrada em 2004, originando a Secretaria da Educação Básica (SEB) e a Secretaria de Educação Profissional e Tecnológica (Setec) (ISLEB, 2014).

O evento foi apresentado pelo MEC como uma estratégia para "[...] reunir para o debate, Governo Federal, Secretarias Estaduais de Educação, pesquisadores e entidades científicas [...]" (BRASIL, 2004, p. 2) e possibilitou a produção de um documento em que predominava o projeto de escola unitária como fundamento para a educação secundária no País.

Assim, somente em 2009, foi publicado o documento Ensino Médio Inovador, depois de analisado e aprovado pelo CNE. Segundo Carlos Artexes 
Simões (informações verbais), ${ }^{7}$ o ProEMI apresenta dois movimentos estruturais e operacionais. $\bigcirc$ primeiro, vigorante em 2010, corresponde ao período que possibilitou maior flexibilidade pedagógica e autonomia na elaboração das propostas curriculares diversificadas pelas escolas, e a reformulação do currículo escolar deveria estar sustentada pelo "entrelaçamento entre trabalho, ciência e cultura" e por vinte e dois indicativos que tratavam, de modo geral, da necessidade de: a) estimular a prática de pesquisa científica e a vivência artístico-cultural no interior das escolas; e b) instituir o letramento, a interdisciplinaridade, os direitos humanos e a participação estudantil como princípios pedagógicos e orientadores da reformulação curricular (BRASIL, 2009b, p. 9).

Embora seja constituído atravessado por discursos de diferentes matrizes teórico-pedagógicas e político-ideológicas, ${ }^{8}$ o Programa carregava a intenção de discutir questões sociais, econômicas e culturais que poderiam ser enfrentadas desde a escola, por meio da elaboração do currículo diversificado, em jornada escolar ampliada.

Em 201 1, quando o Programa assumiu os macrocampos caracterizados como "o conjunto de atividades didático-pedagógicas que estão dentro de uma área de conhecimento percebida como um grande campo de ação educacional e interativa, podendo contemplar uma diversidade de ações que qualificam o currículo escolar" (BRASIL, 201 1, p. 14), são instituídas as fronteiras ordenadas para elaboração das atividades do currículo diversificado nas escolas. Os oito macrocampos propostos: Acompanhamento Pedagógico, Iniciação Científica e Pesquisa, Cultura Corporal, Cultura e Arte, Comunicação e uso de mídias, Cultura Digital, Participação estudantil e Leitura e Letramento se estruturavam como um conjunto de sugestões (idealizações ou prescrições) para o currículo do ensino médio.

Nesse novo cenário, o discurso deixa de ser indicativo e se torna prescritivo. Isso porque, na primeira fase de implantação do Programa,

\footnotetext{
7 Informação prestada pelo ex-diretor de Concepções e Orientações Curriculares para Educação Básica do MEC, em entrevista para esta pesquisa realizada em Recife, dia 27 de março de 2015. 8 A perspectiva de "Desenvolver conhecimentos e habilidades associados a aspectos comportamentais (relacionamento, comunicação, iniciativa, cooperação, compromisso), relativos às atividades de gestão e de iniciativas empreendedoras" (BRASIL, 2009b, p. 10) está diretamente relacionada com o discurso do setor empresarial para o Ensino Médio, questão a ser abordada na seção 5.
} 
coube a cada escola criar as ações pedagógicas considerando as demandas de formação de sua comunidade estudantil; as práticas foram várias e não estavam necessariamente aproximadas das indicações pedagógicas do ProEMI (BRASIL, 2009b). A partir de 201 l, as atividades diversificadas passaram a ser exemplificadas como ações culturais de "efeitos aparentemente já conhecidos": "projetos de estudo e de pesquisas de campo", "fanzine, ${ }^{9}$ informática e tecnologia da informação, rádio escolar, jornal escolar, histórias em quadrinhos, fotografia, vídeos, dentre outros", "Comissão de Meio Ambiente e Qualidade de Vida na Escola; Construir a Agenda 21 na Escola, Grêmio, dentre outros", leitura e interpretação de textos, em estudos sobre autores da literatura local, nacional e estrangeira, e "estudo de línguas estrangeiras." (BRASIL, 201 l, p. 16-17). De modo geral, o discurso oficial atribui mais atenção ao formato que deveria ter o currículo reestruturado do que ao conteúdo político que deveria dar sentido às novas práticas pedagógicas.

Ainda segundo informação do ex-diretor Simões, a criação de macrocampos para demarcar os limites do Projeto de Reestruturação Curricular (PRC) viabilizou a criação de processos mais padronizados de avaliação dos resultados do Programa pelo Ministério da Educação.

De modo geral, a forma de avaliação das atividades do ProEMI ocorreu por meio do envio de relatório on-line pelas escolas às Secretarias de Educação estaduais e pelo preenchimento do Sistema Integrado de Monitoramento do Ministério da Educação (Simec), plataforma virtual do MEC. Logo, não existiu, no período de 2011 a 2015, um processo de acompanhamento das atividades no interior das escolas efetivado pelo MEC. Também, já no documento orientador do Programa de 2011, os exames nacionais de avaliação do desempenho estudantil foram considerados parâmetros para que as escolas identificassem os possíveis efeitos do Programa: "[...] a escola deverá acompanhar as ações em desenvolvimento, avaliando os resultados com base nos principais indicadores

\footnotetext{
9 Tipo de revista que pode ser confeccionada para expressar opinião de forma independente do setor comercial-editorial. A palavra fanzine surgiu da associação de duas outras palavras: fanatic e magazine, que significam fã e revista. Assim, o sentido literal da palavra seria revista de fã. Esse tipo de publicação é usualmente utilizado por artistas e jornalistas independentes.
} 
educacionais e escolares: IDEB, ENEM, índices de aprovação, reprovação, evasão e abandono, dentre outros." (BRASIL, 201 l, p. 18).

Ao longo dos anos, o ProEMI passou por adaptações estruturais diversas. Tais reformulações foram, usualmente, resultantes das demandas apresentadas pelas secretarias de educação dos estados para que o Programa melhor se adequasse às propostas dos sistemas estaduais de ensino público.

É importante registrar que o ProEMI foi inspirado e formulado no postulado filosófico que conceitua a educação integral como a " [...] superação das dicotomias entre humanismo e tecnologia, e entre a formação teórica geral e técnica-instrumental" (BRASIL, 2008, p. 8), porém o documento de 2011 possibilitava que o Programa se apresentasse como se fosse um subsídio financeiro para a implantação ou sustentação dos programas estaduais de reformulação curricular de perspectivas ideológicas diversas.

Como forma de retomar os postulados que embasaram a formulação desse Programa, devemos lembrar que o ProEMI é resultante de uma articulação interministerial e, ao ter sido aprovado por todos os membros do CNE em 2009, destacava o papel da formação secundária como ferramenta de promoção e reestruturação social e, ainda, para a necessidade de criação de:

[...] uma escola que não se limite ao interesse imediato, pragmático e utilitário. Uma formação com base unitária, no sentido de um método de pensar e de compreender as determinações da vida social e produtiva - que articule trabalho, ciência e cultura na perspectiva da emancipação humana. (BRASIL, 2008, p. 8).

A consensualidade dos membros do CNE na aprovação da proposta pode estar relacionada com o fato de, naquele período, existir uma lacuna na instituição de um programa de âmbito federal para o ensino médio não profissionalizante. Assim, era uma demanda política, imediata, e de governo a efetivação de um programa para o ensino médio, conforme informou Simões na entrevista (informações verbais). 
É preciso ressaltar que não havia consenso sobre os fundamentos filosóficos para a institucionalização de uma política nacional para ensino médio no interior do MEC, no período em que o Programa foi formulado (2007-2009), porém, como se tratava da criação de uma ação governamental complementar, o Programa não sofreu resistência em nenhum dos órgãos oficiais por onde passou até ser aprovado, segundo Simões (informações verbais).

Contudo, no cenário mais amplo, desde 1980, existia um conflito entre os grupos de educadores e de movimentos sociais, que defendiam a constituição de um ensino médio de formação cultural ampla e integrada ao mundo do trabalho (FRIGOTTO; CIAVATTA; RAMOS, 2012; KUENZER, 2011), e o empresariado nacional conservador, denominado por Neves (2002) como os liberal-corporativos (empresariado financeiro e grande indústria nacional), que defendiam a execução de políticas governamentais de caráter pragmático e produtivista, visando à formação de mão de obra imediata para o mercado de trabalho.

Dessa forma, resistindo às forças políticas hegemônicas, o ProEMI surgiu no interior do governo assumindo a perspectiva humanista como arcabouço estrutural das práticas do ensino médio. Observava a reestruturação material e a autonomia política e pedagógica das escolas como condição para melhoria da qualidade de ensino ofertado aos jovens:

[...] a qualidade da educação depende menos das estruturas e dos sistemas de ensino do que da unidade escolar com sua progressiva autonomia pedagógica, administrativa e de gestão financeira. A política pública deve promover o fortalecimento da liberdade na educação e o controle social para garantir a igualdade de direitos da população. Para isto é preciso construir uma gestão democrática na escola, mais comprometida com uma sociedade que garanta o direito de todos à educação de qualidade. (BRASIL, 2008, p. 9, grifo nosso).

Embora o Fundo de Manutenção e Desenvolvimento da Educação Básica e de Valorização dos Profissionais da Educação (Fundeb) represente um avanço no financiamento do ensino secundário, visto que já em 2007 a definição dos valores do custo-aluno foi maior para as séries finais do ensino fundamental e 
para o ensino médio (SOUSA JÚNIOR, 2007), a ampliação do número de vagas e principalmente a estrutura operacional física e humana das escolas era, em 2009 (e ainda é), uma questão preocupante para os gestores estaduais.

Em razão disso, houve imediata adesão dos estados à política governamental de diversificação das práticas curriculares e ampliação do turno escolar iniciada pelo governo federal em 2009, por meio da implantação do ProEMI, na qualidade de ação experimental. Visava-se propiciar a elevação dos recursos financeiros direcionados às escolas que apresentavam - ao mesmo tempo em que foram apontadas pelas Secretarias de Educação como unidades capazes de criar - propostas pedagógicas complementares, inovadoras e contextualizadas.

Embora no campo educacional a função do governo federal seja redistributiva e supletiva, a gestão em vigor, no período de 2009-2015. desenvolveu uma forma de reconfigurar a estrutura técnica e pedagógica dos sistemas de ensino nacionalmente, pois a obtenção dos recursos para diversificação curricular e para ampliação do tempo escolar estava determinada pelo estabelecimento de práticas educacionais circunscritas pelos macrocampos, que direcionavam e priorizavam as atividades a serem criadas pelas escolas.

Na etapa inicial do Programa (2009-2010), o valor dos recursos obtidos pelas escolas era definido pelo número de estudantes matriculados no ensino médio. Em 201 1, os recursos foram alterados e estavam diretamente relacionados com o número de estudantes beneficiários do Programa, ou seja, que estavam inseridos nas atividades de tempo integral ou semi-integral desenvolvidas pelas escolas. Era necessária, então, a definição de critérios pelas Secretarias de Educação e pelas escolas para deliberar quais seriam ou não os estudantes e as escolas favorecidos pelo ProEMI. Assim, os critérios passaram a ser definidos pelo projeto político governamental em vigor em cada estado da federação.

Ainda que o lugar político (escola unitária) em que se inscreveu teoricamente o ProEMI não seja explicitamente citado nos documentos orientadores da execução do Programa dos anos 2011, 2013 e 2014 e 
seus textos-diretrizes se organizem em uma perspectiva de ordem técnicoadministrativa, o ProEMI configurava-se como uma possibilidade para o desenvolvimento de ações estruturais no interior da escola (mesmo na égide da pluralidade pedagógica), porque as práticas a serem criadas se referiam a ações curriculares.

\section{EXPANSÃO E TRANSMUTAÇÃO IDEOLÓGICA DO PROEMI}

ProEMI surgiu como experiência-piloto, porém, mesmo sem ter passado por um sólido processo de avaliação que demonstrasse resultados qualitativos e quantitativos, o Programa foi gradativamente expandido pelo MEC. Em três anos de execução, houve um acréscimo de $1.465 \%$ no número de escolas atendidas pelo Programa federal. ${ }^{10}$ Mais que o interesse pela diversificação do currículo escolar, o dado demonstrava a urgente necessidade de redefinir a forma de financiamento do ensino médio no Brasil e o grau de "instabilidade pedagógica" dos sistemas de ensino, pois, para que a adesão fosse realizada, era necessário interesse e anuência da Secretaria de Educação Estadual. Desse modo, qualquer sistema de ensino que tivesse alguma estabilidade financeira e curricular não se inseria em um processo de reformulação curricular sem estabelecer um período mínimo para realizar um exame das possibilidades e limites da inserção do Programa nas escolas; e quando realizada a inclusão das unidades de ensino, na condição de prática experimental, precisava de tempo para avaliar os efeitos sobre a rotina pedagógica das escolas e a formação dos alunos, para, então, decidir ou não pela continuidade do convênio.

Porém as informações - expressas nos relatórios da SEB/MEC dos anos 2008-2009, 2010, 2011, 2012 e 2013 - sobre os gastos do governo federal com o ProEMI mostram que a adesão dos estados foi progressiva e acompanhada pela elevação da adesão do número de escolas, como mostrado na Tabela 1 .

\footnotetext{
10 A informação foi produzida com base nos dados descritos nos Relatórios de Gestão da SEB/ MEC dos exercícios 2008-2009, 2010, 201 1, 2012 e 2013.
} 
Tabela 1 - Número de estados e escolas: adesão e valores gastos com o ProEMI no período 2009-2014

\begin{tabular}{lrrr}
\hline Período & $\begin{array}{c}\text { Número de estados } \\
\text { participantes }\end{array}$ & $\begin{array}{c}\text { Número de escolas } \\
\text { inseridas no Programa }\end{array}$ & Valores \\
\hline 2009 & 14 & 161 & $10.800 .000,00$ \\
2010 & 14 & 355 & $22.570 .000,00$ \\
$2010-2011$ & 18 & 358 & $\begin{array}{r}\text { Complementação } \\
\text { não identificada }\end{array}$ \\
2012 & 25 & 2004 & $\begin{array}{r}\text { 109. 006.000,00 } \\
2013-2014\end{array}$ \\
(Ciclo) & Dado não identifi- & & $169.004 .000,00$ \\
\hline
\end{tabular}

Fonte: Brasil (2016b).

Embora o Programa apresente baixos valores para o financiamento das práticas escolares reestruturadas, se considerarmos as demandas concretas das instituições de ensino, é importante destacar que a expansão do ProEMI, visto exclusivamente como recurso para o financiamento das propostas curriculares dos estados, foi uma das propostas do Conselho Nacional de Secretários Estaduais de Educação (BRASIL, 2012), "1 cuja perspectiva era que o Programa federal permitisse "[...] a inclusão e o respectivo financiamento de outros projetos e iniciativas dos estados e instituições privadas parceiras."

A reivindicação do Consed foi chancelada pelo MEC, por meio da parceria instituída em 2012 com o Instituto Unibanco para o desenvolvimento do Programa Ensino Médio Inovador/Jovem de Futuro (ProEMI/JF). ${ }^{12}$

O Projeto Jovem de Futuro foi criado em 2007 pelo Instituto Unibanco, como "tecnologia de gestão escolar". A ação gerencialista é ofertar apoio

11 Em dezembro de 2012, o Consed, representado pelos secretários de Educação dos Estados do Acre, Distrito Federal, Paraíba e Tocantins, apresentou ao então Ministro de Educação, Aloizio Mercadante, o documento Proposta para avanços no ensino médio, para servir de "base para a construção de ações de curto, médio e longo prazo a ser desenvolvido pelo Ministério da Educação (MEC), tendo como eixo a reformulação curricular, ampliação da educação em tempo integral e maior investimento em infraestrutura." (CONSED, 2012).

12 Sigla oficial do Programa Ensino Médio Inovador/Jovem de Futuro, criada para diferenciar o programa coordenado pelo Instituto Unibanco do programa coordenado pelo governo federal. 
financeiro e técnico às escolas públicas de ensino médio, com vistas a promover a elevação dos índices de aprovação das escolas no Índice de Desenvolvimento da Educação Básica (Ideb) (INSTITUTO UNIBANCO, 2015).

No primeiro ciclo do Projeto (2007-2013), participaram escolas de quatro estados brasileiros: Minas Gerais, Rio de Janeiro, Rio Grande do Sul e São Paulo. Em 2012, quando foi instituída sua vinculação ao ProEMI, seis estados da federação, Ceará, Goiás, Mato Grosso do Sul, Pará, Piauí e São Paulo, associaram o Projeto às suas políticas de gestão educacional.

O ProEMI/JF capacita gestores e técnicos das Secretarias de Educação para apropriação das diretrizes da "Gestão Escolar para Resultados" (INSTITUTO UNIBANCO, 2015). O principal mecanismo pedagógico do Programa era a "supervisão direta e intensiva" dos trabalhos do corpo gestor das escolas e a realização de exames comparativos visando acompanhar os níveis de desempenho cognitivo do corpo estudantil nos exames universais de aferição de aprendizagem.

No "novo modelo do ProEMI", o processo de centralização e de controle do trabalho docente tornou-se o eixo estrutural do Programa. No ProEMI/JF, ofertava-se formação em Metodologias Pedagógicas, na modalidade a distância, que pretendiam orientar (ou determinar) os conteúdos e as práticas a serem desenvolvidas como atividades não disciplinares.

No ProEMI/JF, as formações estavam diretamente relacionadas com o ideário de eficiência e produtividade que se queria fixar às escolas, tendo como referência a elevação do desempenho estudantil em áreas de conhecimento conexas às provas universais de verificação de aprendizagem. Desse modo,

[...] durante o ciclo de três anos de atividades nas escolas de intervenção, cada estabelecimento de ensino deve atuar para conquistar os resultados apontados em seu Plano de Ação. A meta é aumentar em 25 pontos as médias de proficiência em língua portuguesa e matemática, além de diminuir em $50 \%$ o percentual de alunos no padrão de desempenho 'baixo', na escala Saeb (Sistema de Avaliação da Educação Básica), de final do Ensino Médio. $\bigcirc$ pacto prevê ainda que as instituições aumentem em pelo menos 10\% os índices de aprovação nessa etapa escolar. (INSTITUTO UNIBANCO, 201 l, p. 25). 
Observa-se, portanto, a partir da articulação entre os interesses do MEC e do Instituto Unibanco para constituição do ProEMI/JF, que o ideário original do ProEMI - "uma escola que não se limite ao interesse imediato, pragmático e utilitário" (BRASIL, 2008, p. 8) - foi formalmente sobreposto com a instituição do ProEMI/JF pela perspectiva da produtividade, demonstrada por resultados "mensuráveis", como sinônimo de qualidade no ensino público (SILVA, 2013).

ProEMI/JF tinha como objetivos principais elevar o rendimento estudantil e capacitar os jovens para atender às demandas imediatas do mundo do trabalho. $\bigcirc$ Instituto Unibanco, na qualidade de idealizador e gestor direto, pretendia que o

[...] programa, ao assumir essa nova dimensão, tenha um impacto social decisivo e mensurável, contribuindo efetivamente para aumentar a escolaridade dos jovens, que precisam concluir a educação básica para prosseguir seus estudos ou ter as condições mínimas de acesso ao moderno mercado de trabalho. Com o objetivo de avaliar os impactos do ProEMI/Jovem de Futuro, também foi firmada uma nova parceria, dessa vez com a Secretaria de Assuntos Estratégicos da Presidência da República, que atuará nesse processo. (INSTITUTO UNIBANCO, 2011 , p. 7, grifo nosso).

A conjunção ou não funciona no enunciado apenas como um conectivo entre orações, mas como um indicativo de que é possível que os sujeitos da escola realizem ou estejam sujeitos a assumir oposições específicas após o fim da escolarização básica; assim, poderiam "concluir a educação básica para prosseguir seus estudos ou ter as condições mínimas de acesso ao moderno mercado de trabalho." Assim, o prosseguimento da formação e o acesso ao trabalho como direitos sociais eram tratados como se fossem elementos dissociados e uma opção individual, por isso o uso de um recurso linguístico (ou) que significa alternância e exclusão. 
Ainda, no discurso do setor empresarial, a educação secundária é apresentada como ferramenta política capaz de solucionar os problemas sociais:

[...] falta de acesso à educação é o principal fator relacionado à pobreza, a conclusão do nível médio está intrinsecamente vinculada às condições necessárias para a ascensão social. A qualidade e os anos de ensino nessa etapa escolar definem a situação socioeconômica do indivíduo, uma vez que fornecem os requisitos básicos para a entrada no mercado de trabalho, que hoje exige um mínimo de 11 anos de escolaridade, mesmo para o exercício de atividades básicas. (INSTITUTO UNIBANCO, 201 l, p. 11, grifo nosso).

$\bigcirc$ ProEMI/JF estruturou-se pela parceria entre suas instituições do setor empresarial e bancário para estabelecer os conteúdos pedagógicos dos projetos formativos complementares às disciplinas clássicas (nucleares) do ensino médio, e, como consequência, em 2013, um documento orientador do ProEMI, em versão preliminar, foi elaborado pelo MEC e enviado às Secretarias de Educação; depois da consulta, o texto final foi publicado com a substituição da expressão "reestruturação curricular" por "redesenho curricular" (BRASIL, 2013). É importante lembrar que esse movimento ocorreu um ano após a formulação do documento do Consed (Proposta para avanços no ensino médio) e da criação do ProEMI/JF, e o termo reestruturação carregava como sentido político a perspectiva de enfrentamento de questões sociais, não somente pedagógicas, por meio das práticas escolares.

Apesar do processo de silenciamento teórico imprimido aos textos oficiais do ProEMI e de sua limitação operacional, como política complementar, a investida governamental possibilitou, em sua trajetória inicial, ampliar o espaço de disputa ideológica a respeito do sentido social e político que deveria ser atribuído ao ensino médio, que teve como implicação a criação, em 2012, das Diretrizes Nacionais para o Ensino Médio.

Todavia, em outubro de 2016, no movimento de busca pela aprovação da Medida Provisória n. 746/2016, da qual é originária a Lei n. 13.415, de 16 
de fevereiro de 2017, ${ }^{13}$ o Ministério de Educação publicou um novo documentoorientador do ProEMI (2016-2017). O texto apresentou como fundamento para o redesenho curricular "[...] compreender os sujeitos e as juventudes presentes no Ensino Médio brasileiro e seus direitos à aprendizagem e ao desenvolvimento integral." (BRASIL, 2016c, p. 4).

Nessa nova fase do Programa, os macrocampos foram substituídos pelos Campos de Integração Curricular (CICs). No novo formato, o macrocampo Leitura e Letramento foi suprimido do documento, o macrocampo Participação Estudantil foi substituído pelo CIC Protagonismo Juvenil e, ainda, foi criado o CIC Mundo do Trabalho, cujo conteúdo discursivo se associa diretamente à perspectiva de formação profissional no ensino médio:

As ações propostas a partir deste campo de integração curricular deverão propiciar o desenvolvimento de competências essenciais para o exercício de qualquer profissão. $\bigcirc$ desenvolvimento de práticas pedagógicas a partir de vivências com o mundo do trabalho dará início à formação, à discussão de cenários e de oportunidades para a inserção profissional do jovem. As ações propostas no CIC Mundo do Trabalho poderão contemplar uma ou mais áreas de conhecimento com foco na diversidade de temáticas de interesse geral e de conteúdo que articulem com a dimensão do trabalho.

É importante estimular o debate e o pensamento crítico, sem perder de vista o interesse e expectativas da juventude, trazendo informações que contribuam para a escolha dentre as ofertas de formação profissional existentes. As oportunidades no mundo do trabalho dependem diretamente do desempenho escolar, da capacidade de aprender continuamente e da postura e habilidades de leitura, escrita e matemática, adquiridas na formação escolar. (BRASIL, 2016c, p. 12, grifo nosso).

Nesse novo cenário, observa-se um alinhamento dos objetivos do ProEMI à perspectiva de construção de itinerários formativos no ensino médio,

\footnotetext{
13 Trata da "Política de Fomento à Implementação de Escolas de Ensino Médio em Tempo Integral", tendo como estrutura pedagógica a flexibilidade curricular e a implantação do ensino profissionalizante no ensino médio, visando à qualificação restrita do jovem para o ingresso imediato no mercado de trabalho.
} 
mais especificamente a "Formação técnica e profissional", descrita na Lei n. 13.415, de 16 de fevereiro de 2017 (BRASIL, 2017).

A nova Lei apresenta-se como continuidade e ampliação, no campo político-ideológico, da perspectiva de formação desenhada pelo ProEMI/JF. Conforme já discutido, em 2012, o Consed reclamava ao governo federal a necessidade do uso dos provenientes do ProEMI para o "[...] financiamento de outros projetos e iniciativas dos estados e instituições privadas parceiras" (BRASIL, 2012) e como interesse: "Apresenta recomendações para contribuir com a ressignificação do Ensino Médio." Assim, com a mudança de governo em 2016, instituída a partir da efetivação do impeachment da presidente Dilma, os programas e as políticas educacionais passaram a ter maior influência do empresariado nacional; em um cenário político conservador, o discurso em torno da efetivação da educação de tempo integral foi associado ao ideário do ensino profissional em nível médio, como é a concepção do ProEMI/JF.

Em 2016, mediante uma crise econômica e política, ocorreu o impeachment da presidente Dilma Rousseff. A justificativa jurídica para a efetivação da exclusão da presidente do cargo foi a afirmativa de que ela teria cometido crime de responsabilidade fiscal. No cenário de tenso conflito político, foi publicada a Medida Provisória n. 746, de 22 de setembro de 2016 (BRASIL, 2016a), que instituía a "Política de Fomento à Implementação de Escolas de Ensino Médio em Tempo Integral", cujo desdobramento foi a criação da Lei n. 13.415/2017 (BRASIL, 2017). Esta última lançou a perspectiva de construção de itinerários formativos diferenciados no ensino médio e reintroduz, na execução das políticas educacionais, a dualidade histórica do ensino médio, ao (re)dividir esse nível de ensino entre o propedêutico (científico) e o técnico (profissional de baixa qualidade).

Porém, se observamos a postura do Consed (2012) em torno da execução do ProEMI e a articulação instituída pelo governo federal, em 2012, com o Instituto Unibanco, tendo em vista elevar o rendimento estudantil nos exames nacionais e ofertar aos jovens "[...] as condições mínimas de acesso ao moderno mercado de trabalho" (INSTITUTO UNIBANCO, 201 1, p. 7), é possível perceber que o Estado já vinha cedendo espaço ao mercado na definição das práticas do ensino médio, sobretudo às de tempo integral. 
Embora tenha sido motivo de muitas resistências e debates, observase que a reforma do ensino médio, instituída em 2017, foi antecipada pelos vários ciclos de transformação dos objetivos do ProEMI, como Política de Reestruturação (ou de Reforma) do Ensino Médio no Brasil (2009-2016).

Quando criado em 2009, o ProEMI apresentava a diversificação das práticas curriculares e pedagógicas como forma de reestruturar as escolas públicas e de ampliar as experiências culturais dos estudantes do ensino médio. Embora a ampliação da jornada escolar fosse definida como necessária, não era esse o objetivo-fim do Programa. Todavia, por se ter tornado uma das poucas fontes alternativas de recursos financeiros para as escolas estaduais, a ampliação de atividades curriculares foi diretamente associada à ampliação do tempo escolar, visto que não houve um processo de discussão para reformulação das práticas pedagógicas e dos conteúdos das disciplinas clássicas. Logo, a interpretação imediata e autônoma realizada, visto que as escolas não recebiam formações específicas ${ }^{14}$ para o estabelecimento do Programa, foi que, para receber os recursos do ProEMI, era preciso ampliar o tempo escolar. Essa leitura realizou-se possivelmente porque o documento orientador de 2009 afirmava que a Programa deveria ter uma "Carga horária mínima de 3.000 (três mil horas), entendendo-se por 2.400 horas obrigatórias, acrescidas de 600 horas a serem implantadas de forma gradativa." (BRASIL, 2009b, p. 10).

A definição da ampliação da carga horária serviu de ponto de partida para o Consed anunciar o tempo escolar integral como elemento de referência para as políticas estaduais do ensino médio. Desse modo, a concepção política original do Programa foi sobreposta pelos interesses governamentais das gestões estaduais, por isso foi possível canalizar os recursos do ProEMI para financiar a proposta pedagógica criada pelo setor corporativo financeiro, o ProEMI/JF.

\footnotetext{
14 Segundo Simões (2015, informações verbais), dois eventos foram realizados nos espaços do Sesc, em São Paulo e Rio de Janeiro, com a finalidade de demonstrar a estrutura operacional do ProEMI. As ações não foram atividades de caráter formativo mais amplo, com profundidade teórica, mas de um evento "demonstrativo".
} 


\section{CONSIDERAÇÕES FINAIS}

Em um processo contraditório, o Programa federal que surgiu como (ou pretendendo tornar-se) um recurso político contraposto à existência da escola "monocultural", com conhecimentos e práticas disciplinares hierarquizados e gestão vertical, torna-se uma ferramenta de atributo financeiro, já que seus conteúdos teórico, filosófico e político foram silenciados, para a materialização de práticas pedagógicas que produzam sentidos favoráveis à continuidade de um modelo de escola que reforça a histórica e estrutural fragmentação/ dualidade do ensino médio brasileiro. Segundo a Resolução n. 4, de 25 de outubro de 2016 (BRASIL, 2016d, p. 12), que estabeleceu as novas diretrizes para o funcionamento do ProEMI, as inovações curriculares criadas pelas escolas deveriam ser "[...] compatíveis com as perspectivas da sociedade contemporânea e com os anseios dos jovens e adultos, em conformidade com a Medida Provisória n. 746 de 2016." O dispositivo jurídico citado antecedeu e deu sustentação política à Lei n. 13.415 (BRASIL, 2017), que instituiu a Reforma do Ensino Médio, cuja centralidade política tem sido promover articulação do ensino médio com a educação profissional, como correu no cenário neoliberal da década de 1990.

É importante lembrar que os objetivos e resultados da ampliação do tempo escolar estão diretamente relacionados com o tipo de sujeito social que se deseja formar. Logo, no cenário contemporâneo, evidencia-se, por meio do diagnóstico das estruturas do capitalismo, a intensificação do processo de coisificação das relações políticas, culturais e do trabalho (MÉSZÁROS, 2002, 2003). Isso significa que a única saída apresentada pelo discurso hegemônico, aos sujeitos para busca do bem-estar individual, na sociedade de classes contemporânea, tem sido a reacomodação do trabalho, que é tratada como uma ação compulsória ao Estado, que deve impulsioná-la por meio da ampliação da escolarização, cujo ideário de eficiência e de qualidade está diretamente relacionado com os interesses do mercado (das corporações empresariais).

significado do termo reestruturação, que deveria dar sentido às práticas pedagógicas do ProEMI como ação política indutora, estava 
diretamente relacionado com o ideário de "[...] superação do dualismo entre o ensino propedêutico e profissional." (BRASIL, 2008, p. 4). Porém, com a criação do ProEMI/JF e o reordenamento político-pedagógico do ProEMI, expresso no documento-orientador de 2016, observa-se o silenciamento da base filosófica do Programa, que, em 2009, apresentou, pela primeira vez no Brasil, o ideário da educação integral (escola unitária) como fundamento para as políticas de ensino médio regular.

\section{REFERÊNCIAS}

AZEVEDO, J. C.; REIS, J. T. Democratização do ensino médio: a reestruturação curricular no RS. In: AZEVEDO, J. C.; REIS, J. T (Org.). Reestruturação do ensino médio: pressupostos teóricos e desafios da prática. São Paulo: Fundação Santillana, 2013.

BRASIL. Consed entrega ao MEC documento com diagnóstico e propostas de melhorias para o Ensino Médio. 2012. Disponível em: <http://www.consed. org.br/index.php/comunicacao/noticias/567-consed-entrega-ao-mec-documento-com-diagnostico-e-propostas-de-melhorias-do-ensino-medio >. Acesso em: 19 abr. 2015.

BRASIL. Conselho Nacional de Educação (CNE). Resolução n. 3, de 26 de junho de 1998. Institui as Diretrizes Curriculares Nacionais para o Ensino Médio. Diário Oficial da União, Brasília, DF, 05 ago. 1998.

BRASIL. Lei n. 13.415, de 16 de fevereiro de 2017. Altera as Leis $n^{\circ \text { 9 }}$ 9.394, de 20 de dezembro de 1996, que estabelece as diretrizes e bases da educação nacional, e 1 1.494, de 20 de junho 2007, que regulamenta o Fundo de Manutenção e Desenvolvimento da Educação Básica e de Valorização dos Profissionais da Educação, a Consolidação das Leis do Trabalho - CLT...; e institui a Política de Fomento à Implementação de Escolas de Ensino Médio em Tempo Integral. Diário Oficial da União, Brasília, DF, 17 fev. 2017. Disponível em: <http://www.planalto.gov.br/ccivil_03/_ato2015-2018/2017/lei/L13415. htm >. Acesso em: 02 jun. 2017. 
BRASIL. Medida Provisória n. 746, de 22 de setembro de 2016. Institui a Política de Fomento à Implementação de Escolas de Ensino Médio em Tempo Integral, altera a Lei n 9.394, de 20 de dezembro de 1996, que estabelece as diretrizes e bases da educação nacional, e a Lei n ${ }^{\circ} 11.494$ de 20 de junho 2007, que regulamenta o Fundo de Manutenção e Desenvolvimento da Educação Básica e de Valorização dos Profissionais da Educação, e dá outras providências. Brasília, DF, 2016a. Disponível em: <http://www.planalto.gov.br/ ccivil_03/_ato2015-2018/2016/Mpv/mpv746.htm>. Acesso em: 10 dez. 2017.

BRASIL. Ministério da Educação. Relatórios de gestão e planejamento da SEB. 2016b. Disponível em: < http://portal.mec.gov.br/pnaes/195-secretarias-1 12877938/seb-educacao-basica-2007048997/12661-relatorios-de-gestao-e-planejamento-da-seb>. Acesso em: 02 jun. 2017.

BRASIL. Portaria n. 971 , de 09 de outubro de 2009. Diário Oficial da União, Brasília, DF, 13 out. 2009a.

BRASIL. Programa ensino médio inovador: documento orientador: adesão. Brasília, MEC/SEB, 2016c. Disponível em: <http://www.siteal.iipe.unesco. org/sites/default/files/bra_-documento_orientador_adesao_20162017.pdf>. Acesso em: 02 jun. 2017.

BRASIL. Programa ensino médio inovador: documento orientador. Brasília, DF: MEC/SEB, 2013. Disponível em: <http://portal.mec.gov.br/ index.php?option $=$ com_docman\&view $=$ download\&alias $=13249$-doc-orientador-proemi2013-novo-pdf\&category_slug=junho-2013-pdf\&Itemid=30192>. Acesso em: 02 dez. 2014.

BRASIL. Programa ensino médio inovador: documento orientador. Brasília, DF, 2014.

BRASIL. Reestruturação e expansão do ensino médio no Brasil. Brasília, DF, 2008. Disponível em: < http://portal.mec.gov.br/seb/arquivos/pdf/2008/ interministerialresumo2.pdf>. Acesso em: 12 nov. 2014.

BRASIL. Resolução CD/FNDE/MEC n. 4, de 25 de outubro de 2016. Destina recursos financeiros, nos moldes operacionais e regulamentares do Programa Dinheiro Direto na Escola - PDDE, a escolas públicas estaduais e do Distrito Federal, a fim de apoiar e fortalecer o desenvolvimento de propostas curriculares inovadoras, em conformidade com o Programa Ensino Médio Inovador. Brasília, DF, 2016d. Disponível em: <https://www.fnde.gov.br/fndelegis/ action/UrlPublicasAction.php?acao=abrirAtoPublico\&sgl_tipo=RES\&num ato $=00000004 \&$ seq_ato $=000 \& v l r \_a n o=2016 \&$ sgl_orgao $=\mathrm{CD} / \mathrm{FNDE} / \mathrm{MEC}>$. Acesso em: 9 dez. 2017. 
BRASIL. Secretaria de Educação Média e Tecnológica. Documento à sociedade: retorno da Secretaria de Educação Média e Tecnológica do Ministério da Educação às Instituições da Sociedade Civil e Política, pelas contribuições apresentadas no processo de construção da versão final da minuta de decreto que regulamenta os artigos 35 e 36 e 39 a 41 da LDB e revoga o Decreto n. ${ }^{\circ}$ 2.208/97. Brasília, DF, 2004. Disponível em: <http://portal.mec.gov.br/ seb/arquivos/pdf/not25ld.pdf>. Acesso em: 18 jun. 2014.

BRASIL. Secretaria de Educação Básica. Programa ensino médio inovador: documento orientador. Brasília, DF: MEC/SEB, 2009b. Disponível em: <http:// portal.mec.gov.br/dmdocuments/documento_orientador.pdf > . Acesso em: 02 dez. 2014.

BRASIL. Secretaria de Educação Básica. Programa ensino mé-

dio inovador: documento orientador. Brasília, DF: MEC/SEB, 2011.

Disponível em: <http://portal.mec.gov.br/index.php?option=com docman\&view $=$ download\&alias $=9607$-documentoorientador-proemi\&Itemid=30192>. Acesso em: 02 dez. 2014.

CONSED. Proposta para avanços no ensino médio 2012. Brasília, DF, 2012. Disponível em: <http://www.foruns.unicamp.br/foruns/projetocotuca/biblioteca virtual/arquivos/Klinger\%20Marcos\%20Barbosa\%20Alves.pdf>. Acesso em: 05 ago. 2014.

FRIGOTTO, G.; CIAVATTA, M.; RAMOS, M. A gênese do Decreto n. ${ }^{\circ}$ 5.154/2004: um debate no contexto controverso da democracia restrita. In: FRIGOTTO, G.; CIAVATTA, M.; RAMOS, M. (Org.). Ensino médio integrado: concepção e contradições. São Paulo: Cortez, 2012. p. 21-56.

INSTITUTO UNIBANCO. Jovem de futuro. 2015. Disponível em: < http://www. portalinstitutounibanco.org.br/index.php?option $=\mathrm{Com} \_$content\&view $=$article\& $\mathrm{id}=10 \& I t e m i d=8>$. Acesso em: 09 jun. 2015.

INSTITUTO UNIBANCO. Relatórios de atividades 2011. São Paulo: Graf. Ed. Aquarela, 201 l. Disponível em: <http://www.institutounibanco.org.br/wp-content/uploads/2013/09/rel_atividades_IU_2011.pdf>. Acesso em: 09 jun. 2015 .

ISLEB, V. Programa Ensino Médio Inovador (ProEMI): adesão inicial e monitoramento dos dados do fluxo escolar. In: ANPED SUL, 10., 2014, Florianópolis. Anais... Florianópolis, 2014. Disponível em: <http://xanpedsul.faed.udesc. br/arq_pdf/1381-0.pdf>. Acesso em: 09 jun. 2015. 
KUENZER, A. Z. Desafios teóricos-metodológicos da relação trabalho-educação e o papel social da escola. In: FRIGOTTO, G. (Org). Educação e crise do trabalho: perspectivas de final de século. Petrópolis: Vozes, 201 l. p. 55-75.

LOPES, A. R. C. Os parâmetros curriculares nacionais para o ensino médio e a submissão ao mundo produtivo: o caso do conceito de contextualização. Educação e Sociedade, Campinas, v. 23, n. 80, p. 386-400, set. 2002.

MELO, A. A mundialização da educação: consolidação do projeto neoliberal na América Latina, Brasil e Venezuela. Maceió: EDUFAL, 2004.

MÉSZÁROS, I. O século XXI: socialismo ou barbárie? São Paulo: Boitempo, 2003.

MÉSZÁROS, I. Para além do capital. São Paulo: Boitempo, 2002.

MOEHLECKE, S. O ensino médio e as novas diretrizes curriculares nacionais: entre recorrências e novas inquietações. Revista Brasileira de Educação, v. 17, n. 49, jan./abr. 2012.

NEVES, L. M. W. O neoliberalismo e a redefinição das relações estado-sociedade. In: NEVES, L. M. W. (Org.). O empresariado da educação: novos contornos do ensino superior no Brasil dos anos 1990. São Paulo: Xamã, 2002.

ORLANDI, E. As formas do silêncio: no movimento dos sentidos. Campinas: Ed. Unicamp, 2007.

RAMOS, M. A. Concepção do ensino médio integrado: anexo. In: PARÁ. Secretaria de Estado e Educação. O ensino médio integrado no Pará como política pública. Belém: Seduc, 2009.

RAMOS, M. A. Educação profissional pela pedagogia das competências e a superfície dos documentos oficiais. Educação e Sociedade, Campinas, v. 23, n. 80, p. 401-422, set. 2002 .

RAMOS, M. A. Possibilidades e desafio na organização do currículo integrado. In: FRIGOTTO, G.; CIAVATTA, M.; RAMOS, M. (Org.). Ensino médio integrado: concepções e contradições. São Paulo: Cortez, 2005.

RODRIGUES, J. Ainda a educação politécnica: o novo decreto da educação profissional e a permanência da dualidade estrutural. Trabalho, Educação e Saúde, v. 3 n. 2, p. 259- 282, 2005.

SAVIANI, D. Sobre a concepção de politecnia. Rio de Janeiro: EPSJV/Fiocruz, 1989. 
SILVA, M. Juventudes e ensino médio: possibilidades diante das novas DCN. In: AZEVEDO, J. C.; REIS, J. T. (Org.). Reestruturaçaõ do ensino médio: pressupostos teóricos e desafios da prática. São Paulo: Fundação Santillana, 2013. p. 65-79.

SOUSA JÚNIOR, L. Fundeb: novo fundo, velhos problemas. In: REUNIÃO ANUAL DA ANPED, 30., 2007, Caxambu. Anais... Rio de Janeiro: Anped, 2007. Disponível em: <http://30reuniao.anped.org.br/trabalhos/GT05-3091--Int. pdf>. Acesso em: 29 jul. 2011.

Recebido em:: 20 de agosto de 2017 Aceito em:: 04 de abril de 2018

Endereço para correspondência: Avenida Lourival Melo Mota, Cidade Universitária, 57072-000, Maceió, Alagoas, Brasil; agiordanna@hotmail.com 